\title{
Theoretical Study of the Mechanism and Rate Constant Calculations of the Reaction of Carbon Monoxide with Ethylene
}

\author{
Washington B. Silva \& Alessandra F. Albernaz
}

\section{Introduction}

The $\mathrm{CO}+$ ethylene $\left(\mathrm{C}_{2} \mathrm{H}_{4}\right)$ reaction participate as product in important chemical processes of class of fuels in combustion. ${ }^{1,2}$ Investigation on the reactions of hydrocarbons with some atmospheric species can provide significant insights into combustion, hydrocarbon synthesis, interstellar space and atmospheric chemistry. Ethylene is one of the highest volume chemicals produced globally. ${ }^{3,4}$ In addition, ethylene is an important element in petrochemical industry. ${ }^{5}$ The study of reaction $\mathrm{CO}+\mathrm{C}_{2} \mathrm{H}_{4}$ give support to understanding the whole combustion mechanism and is useful for establishing appropriate models for combustion simulations under the atmospheric condition.1 In this work we investigated the pathways reaction of the $\mathrm{CO}+$ ethylene reaction. Initial

equilibrium geometries of the reactions, intermediate reactions, transitions states, and product were optimized at density functional CBS-QB3 ${ }^{6}$ to all species involved in the reaction. The rate constant has been calculated using transition state theory ${ }^{7}$ and Wigner, Eckart tunneling correction factor ${ }^{7,8,9}$ and writing down in the Arrhenius form for temperature range of $100-4000 \mathrm{~K}$.

\section{Methods}

\section{TRANSITION STATE THEORY}

Based on the transition state theory, the thermal rate constant $(\mathrm{TRC})$ of a bimolecular reaction, $\mathrm{A}+\mathrm{BC} \rightarrow \mathrm{TS}$ $\rightarrow \mathrm{C}+\mathrm{AB}$ can be written $\mathrm{as}^{8}$ :

$$
k^{\mathrm{TST}}=\frac{K_{B} \mathrm{~T}}{h} \frac{Q^{\mathrm{TS}}}{Q^{R}} \exp \left(-\frac{\mathrm{V}}{R T}\right)
$$

where $\mathrm{KB}$ and $\mathrm{h}$ are Boltzmann and Planckconstants, while $\mathrm{T}$ is the temperature and $\mathrm{R}$ i s the universal gas constant. $\mathrm{Q}^{\mathrm{TS}}$ and $\mathrm{Q}^{\mathrm{R}}\left(\mathrm{Q}^{\mathrm{A}} \mathrm{Q}^{\mathrm{BC}}\right)$ are the partition functions of transition state (TS) and reactant $(\mathrm{R}=\mathrm{A}+\mathrm{BC})$, respectively. In this work, we have considered two corrections for the tunneling effect: Wigner $(\mathrm{KW}(\mathrm{T}))$ and Eckart $\left(\mathrm{K}_{\mathrm{E}}(\mathrm{T})\right)$. The Wigner transmission coefficient is given by ${ }^{7,8}$

$$
\kappa_{W}(T)=1+\frac{1}{24}\left|\frac{h \omega^{\ddagger}}{k_{B} T}\right|^{2}
$$

and the Eckart tunneling correction $\left(\mathrm{K}_{\mathrm{E}}(\mathrm{T})\right)$ is obtained solving the Schrödinger equation for the $V$ : 


$$
\kappa_{E}(T)=\frac{\exp \left(\Delta V^{T S} / R T\right)}{R T} \int_{0}^{\infty} \exp (-E / R T) \Gamma(E) d E
$$

here the transmission probability $(\Gamma(E))$ is given by:

$$
\Gamma(E)=1-\frac{\cosh [2 \pi(\alpha-\beta)]+\cosh [2 \pi \gamma]}{\cosh [2 \pi(\alpha+\beta)]+\cosh [2 \pi \gamma]}
$$

with

$$
\begin{array}{r}
\alpha=\frac{1}{2}(E / c)^{1 / 2}, \quad \beta=\frac{1}{2}\left(\frac{E-a}{C}\right)^{1 / 2}, \\
\gamma=\frac{1}{2}\left(\frac{b-C}{C}\right)^{1 / 2} \text { and } c=\frac{\left(h \omega^{T S}\right)^{2} B}{16 \Delta V^{T S}\left(\Delta V^{T S}-a\right)} .
\end{array}
$$

The TRC were then written in the Arrhenius form as:

$$
k(T)=A T^{n} \exp \left(-\frac{E_{a}}{R T}\right)
$$

where $A$ is the pre-exponential factor, $\mathrm{n}$ is the temperature power factor and $\mathrm{E}_{\mathrm{a}}$ is the activation energy.

\section{AB INITIO CALCULATIONS}

The CBS-QB3 method ${ }^{6}$ encompasses the so called complete basis set model chemistries originally developed by Peterson and coworkers. CBS models involve low-level (SCF and ZPE) calculations on large basis sets, mid-sized sets for second-order corrections, and small sets for high-level corrections. They include extrapolation to the complete basis sets to correct MøllerPlesset second-order energies in addition to empirical and spin-orbit interaction corrections. ${ }^{10-16}$ Specifically, the CBSQB3 method involves the following steps:

i. B3LYP/6-311G(2d,d,p) geometry optimazation.

ii. B3LYP/6-311G(2d,d,p) frequencies with a 0.99 scale factor for the ZPE.

iii. UMP2/6-311+G(3d2f,2df,2p) energy and CBS extrapolation.

iv. $M P 4(S D Q) / 6-31+G(d(f), p)$ energy.

v. $\operatorname{CCSD}(\mathrm{T}) / 6-31+\mathrm{G}^{*}$ energy. Finally, the total and free energy are calculated from the following:

$$
\begin{aligned}
E_{\mathrm{CBS}-\mathrm{QB} 3} & =E_{\mathrm{MP} 2}+\Delta E_{\mathrm{MP} 4}+\Delta E_{\mathrm{CCSD}(\mathrm{T})} \\
& +\Delta E_{\mathrm{ZPE}}+\Delta E_{\mathrm{CBS}}+\Delta E_{\mathrm{emp}}+\Delta E_{\mathrm{int}}, \\
G_{\mathrm{CBS}-\mathrm{QB} 3} & =E_{\mathrm{MP} 2}+\Delta E_{\mathrm{MP} 4}+\Delta E_{\mathrm{CCSD}(\mathrm{T})} \\
& +\Delta E_{\text {thermalcorrection }}+\Delta E_{\mathrm{CBS}}+\Delta E_{\mathrm{emp}} \\
& +\Delta E_{\mathrm{int}}
\end{aligned}
$$

where $\triangle \mathrm{ECBS}$ is the term correcting the basis set truncation error in the second-order energies, and the energy terms $\triangle \mathrm{EMP} 4, \Delta \mathrm{ECCSD}(\mathrm{T}), \Delta \mathrm{Eemp}$, and $\Delta$ Eint are calculated from the following respective equations:

$$
\begin{gathered}
\Delta E_{M P 4}=E_{M P 4(S D Q) / 6-31+G(d(f), p)}- \\
E_{M P 2 / 6-31+G(d(f), p)} \\
\Delta E_{\mathrm{CCSD}(\mathrm{T})}=E_{\mathrm{CCSD}(\mathrm{T}) / 6-31+\mathrm{G}^{*}} \\
-E_{\mathrm{MP} 4(\mathrm{SDQ}) / 6-31+\mathrm{G}^{*}} \\
\Delta E_{\text {emp }}=-0.00579 \sum_{i=1}^{n_{\beta}}\left(\sum_{\mu=1}^{N_{\text {virt }+1}} C_{\mu_{i i}}\right)^{2}|S|_{i i}^{2} \\
\Delta E_{\text {int }}=-0.00954\left[\left\langle S^{2}\right\rangle-S_{z}\left(S_{z}-1\right)\right] .
\end{gathered}
$$

The CBS-QB3 method has been employed in our work to optimize the geometries of the reactant, complex reactants, transition states, complex products and products of the reaction of carbon monoxide with ethylene $\left(\mathrm{CO}+\mathrm{C}_{2} \mathrm{H}_{4}\right)$. Vibrational frequencies calculated at CBS-QB3 levels were used for characterization of stationary points as minima and transition states, for zero-point energy (ZPE) corrections, because it is known that the ZPE value is significant in hydrogen-bonded systems. ${ }^{17}$ The number of imaginary frequencies $(0$ or 1) indicates whether a minimum or a transition state has been located. To confirm that the transition state really connects with designated intermediates along the reaction path, the intrinsic reaction coordinate (IRC) ${ }^{18}$ calculations were performed. Also, the IRC calculations were used to confirm the connection between the designated transition states and the reactants or products. All quantum chemistry calculations were performed with Gaussian 09 program. ${ }^{19}$ 


\section{Results and Discussion}

The relative energies (the total energy of the reactants is set to zero for reference) of all species involved at the CBS-QB3 level are summarized in Figure 1.

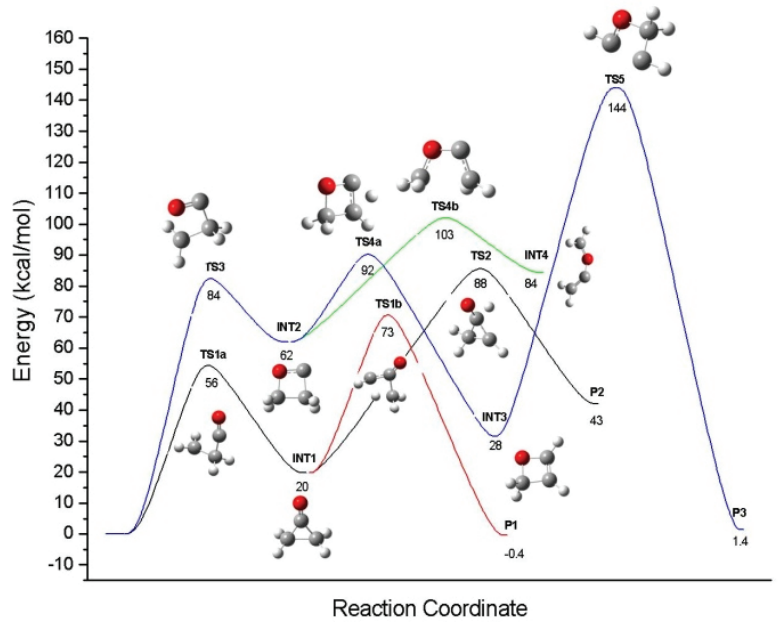

Figure 1. Potential energy diagram for decomposition of $\mathrm{CO}+\mathrm{C}_{2} \mathrm{H}_{4}$ reaction at the CBS-QB3 level.

During the simulations, we found four pathways for the Potential Surface Energy - SEP. We found some pathways that were proposed by Karami and Vahedpour1 and we found two news pathways. Our results for the reactants, intermediates and products are in good agreement compared with results obtained by Karami and Vahedpour, and all real frequencies and any transition state has only one imaginary frequency.

In Table 1 we display the rate constant for the $\mathrm{CO}+$ $\mathrm{C}_{2} \mathrm{H}_{4} \rightarrow \mathrm{C}_{2} \mathrm{H}_{3} \mathrm{COH}$ reaction to temperature of $250 \mathrm{~K}$.

Table 1: Conventional (kTST), Wigner $\left(k^{\mathrm{TST}}\right)$, and Eckart $\left(k_{\mathrm{E}}^{\mathrm{TST}}\right)$ thermal rate constants calculated for the $\mathrm{CO}+\mathrm{C}_{2} \mathrm{H}_{4} \rightarrow \mathrm{C}_{2} \mathrm{H}_{3} \mathrm{COH}$ reaction at $250 \mathrm{~K}$.

\begin{tabular}{|c|c|}
\hline T(K) & kTST [cm3.molecule-1.s-1] \\
\hline \multirow{3}{*}{250} & $1.57 \times 107\left(k^{\mathrm{TST}}\right)$ \\
\cline { 2 - 2 } & $3.99 \times 107\left(k_{\mathrm{w}}^{\mathrm{TST}}\right)$ \\
\cline { 2 - 2 } & $3.46 \times 1028\left(k_{\mathrm{E}}^{\mathrm{TST}}\right)$ \\
\hline
\end{tabular}

\section{Conclusions}

In this work, the $\mathrm{CO}+\mathrm{C}_{2} \mathrm{H}_{4}$ reaction potential energy profiles were determined based on the geometrical optimization, frequency and energy calculations at the CBS-QB3 level. Our simulations for the SEP predicted two new pathways for the $\mathrm{CO}+\mathrm{C}_{2} \mathrm{H}_{4}$ reaction and for the others paths presented in good concordance with SEP investigated by Karami and Vahedpour. The thermal rate constants showed high possibility of occurrence at room temperature for the pathway studied.

\section{Acknowledgments}

The authors are grateful for the support given from the Instituto Federal de Educação, Ciência e Tecnologia do Goiás - IFG.

\section{References}

1. F. Karami and M. Vahedpour, J. Iran Chem Soc.,11,781, (2014).

2. H. Hua, B. Ruscic, B. Wang, Chem. Phys., 311, 335, (2005).

3. Assessment report on ethylene for developing ambient air quality objectives, http://gov.ab.ca/env/protenf/standards/index.html. Alberta Environ (2003).

4. Production: Growth is the Norm//Chemical and Engineering News, 84, 28 (2006). http://pubs.acs.org/cen/coverstory/84/ pdf/8428produ tion.pdf

5. A. Lifshitz, H. Ben-Hamou, J. Phys. Chem., 87, 1782 (1983).

6. J. A. Montgomery, M. J. Frisch, J. W. Ochterski, G.A. Pertersson., J. Chem. Phys., 110, 2822 (1999).

7. E. Henon, F. Bohr, Journal of Molecular Structure (Theochem), 531,283 (2000).

8. D. G. Truhlar, A. D. Isaacson, B. C. Garrett, Generalized Transition State Theory, Series: Theory of Chemical Reaction Dynamics. CRC Press, Inc., vol. 4, p. 65, (1985).

9. C. Eckart, Phys. Rev. 35, 1303 (1930).

10. Ochterski, J. W.; Petersson, G. A.; Montgomery, J. A., Jr. J Chem Phys, 104, 2598 (1996).

11. Nyden, M. R.; Petersson, G. A. J Chem Phys, 75, 1843 (1981).

12. Petersson, G. A.; Bennett, A.; Tensfeld, T. G.; Al-Laham, M. A.; Shirley, W.; Matzaris, J. J Chem Phys, 89, 2193 (1988).

13. Petersson, G. A.; Al-Laham, M. A. J Chem Phys, 94, 6081 (1991).

14. Petersson, G. A.; Yee, A. K.; Bennett, A. J Chem Phys, 83, 5105 (1983).

15. Montgomery, J. A., Jr.; Ochterski, J. W.; Petersson, G. A. J Chem 


\section{Artigo Geral 59}

Phys, 101, 5900 (1994).

16. Montgomery, J. A., Jr.; Frisch M. J.; Ochterski, J. W.; Petersson, G. A. J Chem Phys, 112, 6532 (2000).

17. O. Mó, M. Elguero Yáñez, J. Chem. Phys. 97, 6628 (1992).

18. K. Raghavachari, G. W. Trucks, J. A. Pople, M. Head-Gordon, Chem. Phys. Lett. 157, 479 (1989).

19. Frisch, M. J. et al. Official Gaussian 09 Literature Citation. Gaussian, Inc.: Pittsburgh PA (2009).

20. http://www.gaussian.com/g_tech/g_ur/m_citation.htm

\section{Washington Barbosa da Silva ${ }^{a, b}$ \& Alessandra F. Albernaz $^{a}$}

anstituto de Física, Universidade de Brasília, Brasília, DF, Brazil

'Instituto Federal de Educação, Ciência e Tecnologia do Goiás- IFG, GO, Brazil 